\title{
SCOLIOSIS IN JUVENILE RHEUMATOID ARTHRITIS
}

\author{
J. J. Rombouts and C. Rombouts-Lindemans, Louvain, Belgium
}

From the Rheumatism Foundation Hospital, Heinola, Finland, and the

Alfred I. duPont Institute of the Nemours Foundation, Wilmington, Delaware, United States of America

In juvenile rheumatoid arthritis, involvement of the cervical spine is common and well documented (Still 1897; Potter, Barkin and Stillman 1954; Le Baudour and Freyberg 1958). Involvement of the thoracic and lumbar spine is not frequent but was mentioned by Forestier, Jacqueline and Canet (1959), by Grokoest, Snyder and Schlaeger (1962) and by Martel, Holt and Cassidy (1962). Furthermore, growth disturbances in this area may occur, particularly in the more severe forms of rheumatoid disease (Forestier et al., Grokoest et al.). The failure of normal growth is closely associated with the activity of the disease (Ansell and Bywaters 1956). Although Grokoest et al. asserted that the total reduction in height of such patients may be partly due to thoracic kyphosis or scoliosis, we have been unable to find in the literature a study on scoliosis in this disease.

The purpose of this paper is to report eleven patients who had suffered from juvenile rheumatoid arthritis and who had developed a structural scoliosis of the thoracic or lumbar spine. Eight cases were found during a systematic retrospective study at the Rheumatism Foundation Hospital and three additional cases stem from the Alfred I. duPont Institute.

\section{CASES FROM THE RHEUMATISM FOUNDATION HOSPITAL MATERIAL AND METHOD}

For a previous study (Rombouts and Rombouts-Lindemans 1971), the records of 455 children with juvenile rheumatoid arthritis treated between 1951 and 1969 were reviewed. All of them met the diagnostic criteria proposed by Ansell, Bywaters and Lawrence (1962). The sex ratio was similar to that in previous series (Laaksonen 1966): 323 (71 per cent) were girls and 132 (29 per cent) boys. Of these, 124 were followed up to the end of the growth period, when they were classified according to the various stages of the disease (Steinbrocker, Traeger and Batterman 1949) (Table I).

TABLE I

Classification of Stage of the Disease

\begin{tabular}{|c|c|c|}
\hline Stage & ! & $\begin{array}{l}\text { Number of } \\
\text { patients }\end{array}$ \\
\hline I -Early & & 7 \\
\hline II -Moderate. & & 33 \\
\hline III-Severe & & 36 \\
\hline IV-Terminal . & & 48 \\
\hline Total & & 124 \\
\hline
\end{tabular}

No systematic radiographs of thoracic and lumbar spine were available, but each patient on every admission to the hospital had routine radiographs of the chest and of the affected joints. Thus we found eight cases of scoliosis with a curve of over 20 degrees as measured by the method of Cobb (1960). 
FINDINGS

The common feature of these eight young adult patients-six men and two women-was severe and long-standing disease (Table II). Six were under the age of seven at the onset. Two had positive tests for rheumatoid factor and one (Case 5) had severe systemic involvement. Four had had corticosteroids in high dosage during the growth period. At the end of growth

TABLE II

Detalls of the Disease in Eight Patients

\begin{tabular}{|c|c|c|c|c|c|c|c|}
\hline $\begin{array}{c}\text { Case } \\
\text { number }\end{array}$ & Sex & $\begin{array}{c}\text { Age at } \\
\text { onset } \\
\text { (years) }\end{array}$ & $\begin{array}{l}\text { Rheumatoid } \\
\text { factor }\end{array}$ & Corticotherapy & $\begin{array}{l}\text { Activity of } \\
\text { disease at } \\
\text { end of growth }\end{array}$ & Stage & $\begin{array}{l}\text { Cervical } \\
\text { ankylosis }\end{array}$ \\
\hline 1 & Female & 4 & - & From 12 to 14 & + & IV & + \\
\hline 2 & Female & 2 & - & None & + & IV & + \\
\hline 3 & Female & 6 & + & From 8 to 10 & + & IV & + \\
\hline 4 & Female & 4 & - & None & + & IV & + \\
\hline 5 & Male & 6 & - & From 10 to 14 & + & IV & + \\
\hline 6 & Female & 12 & + & From 15 to 16 & + & IV & - \\
\hline 7 & Male & 11 & - & None & Not known & IV & + \\
\hline 8 & Female & 5 & - & None & + & IV & + \\
\hline
\end{tabular}

TABLE III

Details of the Curvatures in Eight Patients

\begin{tabular}{|c|c|c|c|c|c|c|}
\hline \multirow{2}{*}{$\begin{array}{c}\text { Case } \\
\text { number }\end{array}$} & \multirow{2}{*}{$\begin{array}{l}\text { Site of } \\
\text { curve }\end{array}$} & \multirow{2}{*}{$\begin{array}{l}\text { Side of } \\
\text { convexity }\end{array}$} & \multirow{2}{*}{$\begin{array}{c}\text { Age at } \\
\text { onset of } \\
\text { curvature } \\
\text { (years) }\end{array}$} & \multirow{2}{*}{$\begin{array}{c}\text { Age at fusion } \\
\text { of iliac } \\
\text { apophyses } \\
\text { (years) }\end{array}$} & \multicolumn{2}{|c|}{ Last examination } \\
\hline & & & & & $\begin{array}{c}\text { Age } \\
\text { (years) }\end{array}$ & $\begin{array}{c}\text { Angulation } \\
\text { (degrees) }\end{array}$ \\
\hline 1 & T.9 to L.4 & Left & 15 & 18 & 28 & 70 \\
\hline 2 & T.7 to L.3 & Right & 9 & 19 & 20 & 75 \\
\hline 3 & $\mathrm{~T} .1$ to $\mathrm{T} .11$ & Left & 10 & 20 & 20 & 33 \\
\hline 4 & T.3 to T.8 & Right & Before 17 & 19 & 29 & 40 \\
\hline 5 & $\begin{array}{l}\text { T.4 to T.9 } \\
\text { T.9 to L.5 }\end{array}$ & $\begin{array}{l}\text { Right } \\
\text { Left }\end{array}$ & 11 & 20 & 20 & $\begin{array}{l}55 \\
45\end{array}$ \\
\hline 6 & T.1 to T.6 & Left & 13 & 19 & 23 & 25 \\
\hline 7 & T.12 to L.4 & Left & Not known & Not known & 33 & 30 \\
\hline 8 & T.1 to T.9 & Left & Not known & Not known & 36 & 35 \\
\hline
\end{tabular}

the disease was still active in all cases, and according to the classification of Steinbrocker $e t$ al. they belonged to the Stage 4 of the disease. Seven had ankylosis of the cervical spine.

The characteristics of the curves are summarised in Table III. Four were thoracic, three thoraco-lumbar and one double. Five single curvatures were to the left and two to the right. The age of onset of the curvature was under eleven years in three cases, and between eleven and the end of growth in another three; two cases were first noticed after growth had ceased. The severity of the curve at the last examination was between 20 and 45 degrees in five cases, and more than 45 degrees in three cases, respectively 55, 70 and 75 degrees. All these patients 


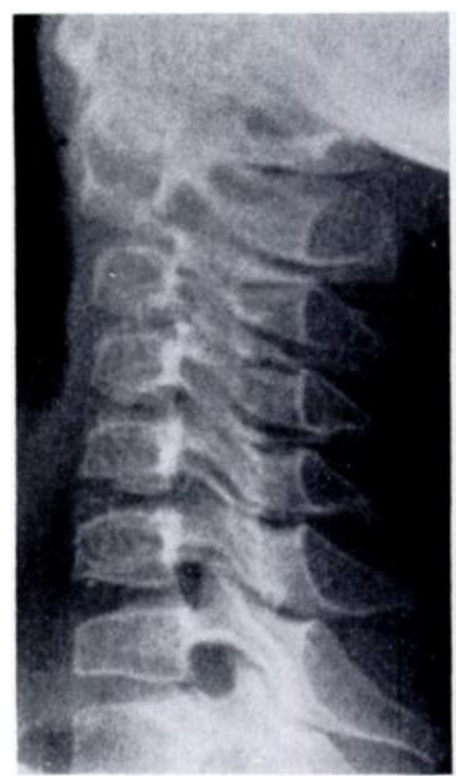

FIG. 1

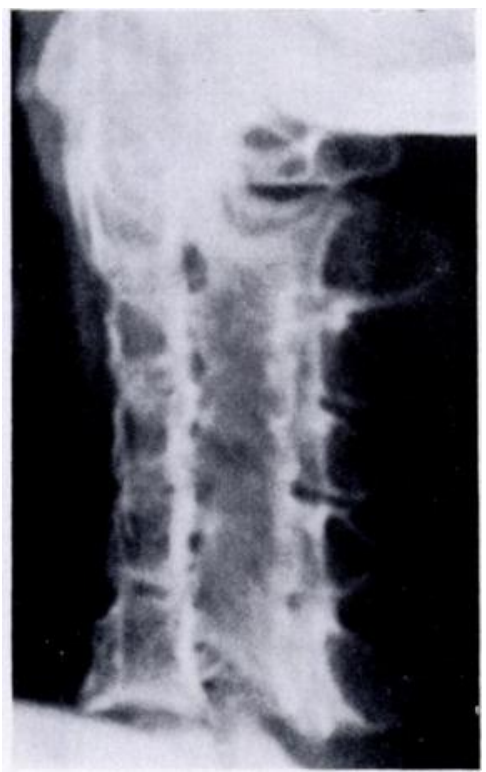

FIG. 2

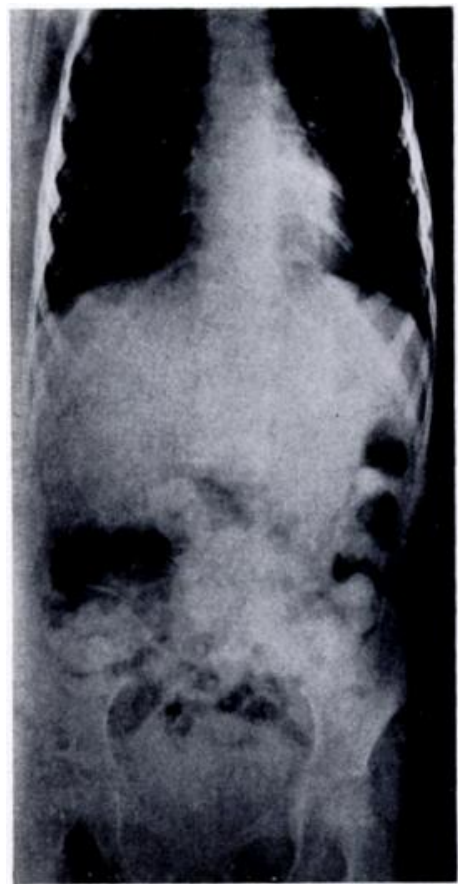

Fig. 3

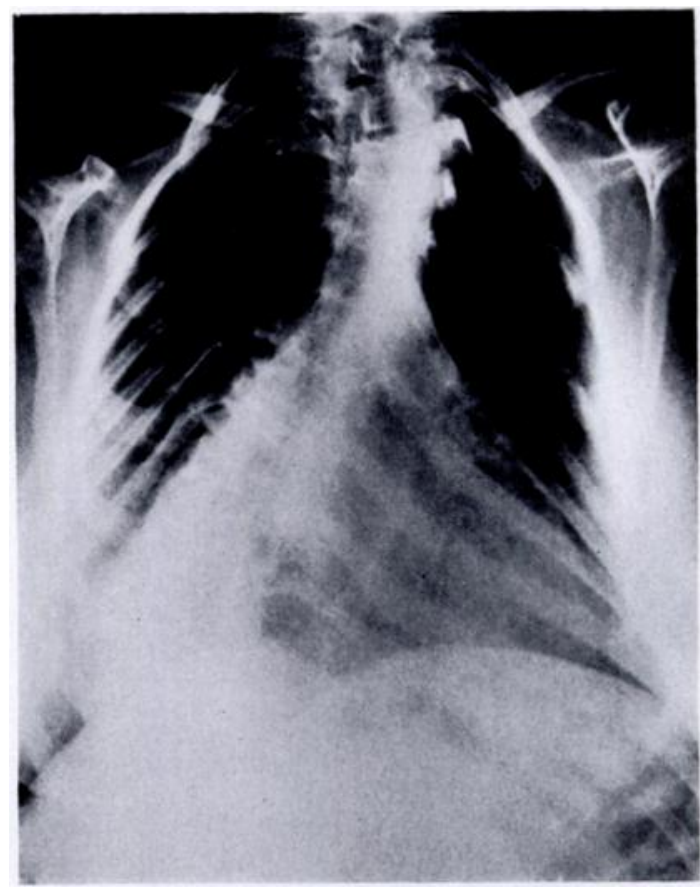

Fig. 4

Case 2-A girl with juvenile rheumatoid arthritis since the age of 2 years. Figure 1-Lateral radiograph of the cervical spine at the age of 8 . Figure 2-At the age of 15, severe and extensive involvement of the cervical spine has led to ankylosis. Figure 3-A plain radiograph of the abdomen at the age of 5 shows no significant curvature. Figure 4-At the age of 15 there is a thoraco-lumbar scoliosis of 75 degrees to the right, from T.7 to L.3. 
had vertebral rotation, although this was moderate in Cases 3, 4, 5 and 6. In Case 3, spina bifida occulta of the first thoracic vertebra was present. In four cases $(3,4,5$ and 6) the intervertebral space at the apex of the curve appeared narrowed and irregular before the onset of the curvature. Dorsal pain was noted in the records of these patients, and this suggested rheumatoid involvement. Most of the patients had abnormal lumbar vertebral bodies with a short antero-posterior diameter (Fig. 7) as described by Forestier $e$ t al. and Grokoest et al. The average age of complete fusion of the iliac apophyses was nineteen. As compared with the data of Köhler and Zimmer (1953) from a normal population and of Zaoussis and James (1958) from scoliotic patients, the growth of the iliac apophysis appeared unaffected by the disease. No orthopaedic or surgical treatment was attempted for these curvatures.

\section{ADDITIONAL CASES FROM \\ THE ALFRED I. dUPONT INSTITUTE CASE REPORTS}

Case 9-In 1962 a boy aged two developed rheumatoid arthritis with involvement of elbows, wrists, knees and ankles. At the age of six he was seen with swelling and limitation of these joints, pneumonitis and moniliasis. At the age of ten he showed stiffness of the spine and shoulders, and flexion contractures of the hips, knees and wrists. Plain radiographs showed slight narrowing of the T.9-10 and T.10-11 intervertebral spaces and a curve of 20 degrees to the right from T.9 to L.1, with mild rotation. Case 10-A boy aged twelve was first seen in 1964 for pain and mild swelling of the ankles and elbows. Rheumatoid arthritis was suspected. By the age of fifteen he had developed flexion contractures of the lower limbs and walked with an increased lumbar lordosis. The rheumatoid disease was still severe and active two years later. By the age of eighteen, when he was bedridden, he had developed a left thoraco-lumbar curve of 65 degrees from T.5 to L.3 (Fig. 8).

Case 11-In 1970 a girl aged sixteen was first seen. She had developed rheumatoid arthritis at the age of fourteen months and had had corticosteroid therapy for a period of ten years. The mother noticed scoliosis when the girl was thirteen while the disease was in remission, and this progressively increased. By the age of sixteen she had a double curve to the right from T.3 to T.12 measuring 45 degrees, and a curve to the left from T.12 to L.5 measuring 80 degrees.

\section{DISCUSSION}

Shands and Eisberg (1955) in a review of 50,000 chest radiographs taken in the course of mass miniature radiographs found 936 with evidence of scoliosis, an incidence of 1.9 per cent. Of these, 0.5 per cent exceeded 20 degrees. In the series of the Rheumatism Foundation Hospital, the incidence of curves over 20 degrees in juvenile rheumatoid arthritis was 1.7 per cent $(8 / 455)$ of the cases reviewed. For patients who had reached maturity the incidence was 6.5 per cent $(8 / 124)$. Actually, all the patients with scoliosis had reached the terminal stage of the disease, and now the incidence was 16.6 per cent $(8 / 48)$. This represents a thirtyfold increase as compared with the incidence in a normal population, which cannot be fortuitous.

However, the mechanism which leads to spinal deformity is not evident. It seems probable 


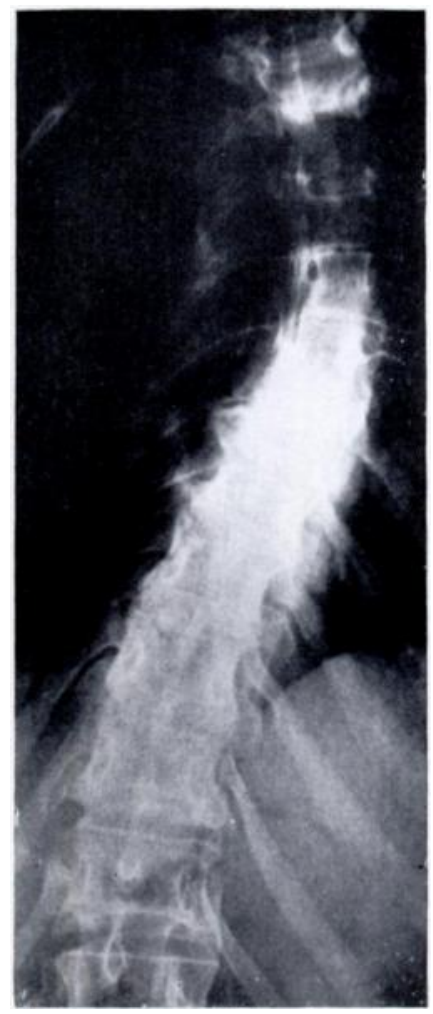

Fig. 6

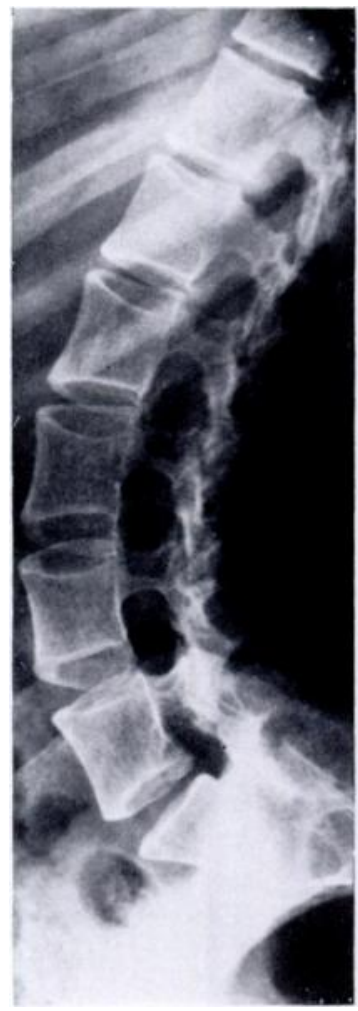

Fig. 7

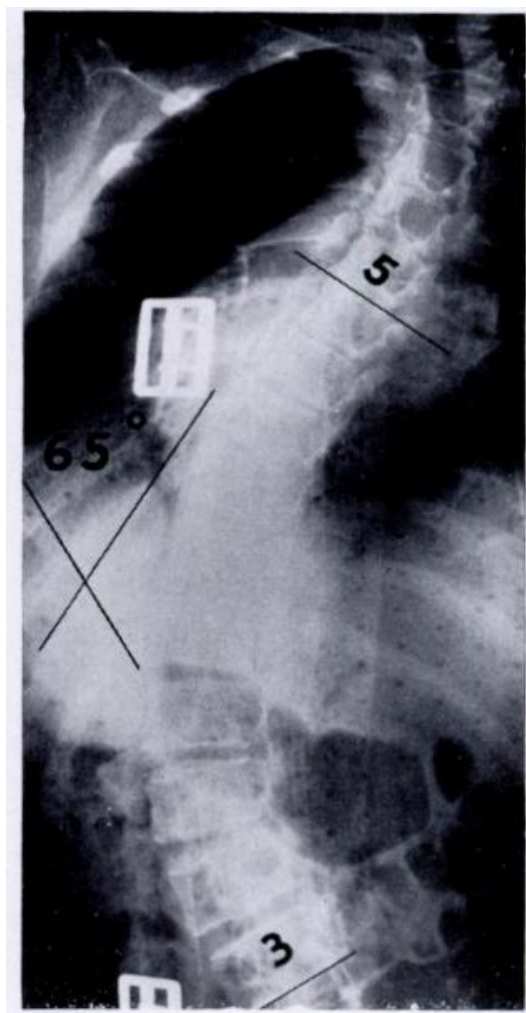

Fig. 8

Case 8. Figures 6 and 7-This patient was first seen at the age of 36. The disease started at the age of 5 and was still active. She had complete cervical ankylosis. Figure 6-The antero-posterior radiograph of the thoracolumbar spine showing a curve of 35 degrees to the left, from T.1 to T.9. The intervertebral spaces appear narrowed and there are mild marginal irregularities of the upper thoracic vertebral bodies. Figure 7-A lateral radiograph of the lumbar spine showing abnormal vertebral bodies with short antero-posterior diameters. Case 10. Figure 8-This boy with juvenile rheumatoid arthritis since the age of 12 presented at the age of 18 with a thoraco-lumbar scoliosis of 65 degrees to the left from T.5 to L.3.

that several factors are operating simultaneously. In every severe case of juvenile rheumatoid arthritis general and regional growth disturbances, osteoporosis and extensive muscle atrophy are present (Ansell and Bywaters 1956) and must be considered as predisposing factors. Furthermore, rheumatoid involvement of the spine may occur.

As emphasised by James (1970), each known etiology of scoliosis has its characteristic curves and site of curvature. In juvenile rheumatoid arthritis we have observed two patterns. In Cases 1, 2, 7, 10 and 11 there was a long curve involving many vertebrae, suggesting muscle imbalance as the determining factor (Figs. 4 and 8). In Cases 3, 4, 5, 6 and 9 few vertebrae were involved and the vertebral rotation was moderate (Fig. 5). In these latter cases we noted dorsal pain before the onset of the curvature, with narrowing of the disc space and mild marginal irregularities of the vertebral bodies as described by Grokoest et al. Although involvement of the thoracic and lumbar spine is very uncommon in this disease, it seems possible that the starting point of these latter curvatures was asymmetrical involvement of the inter-apophyseal joints. Disc space involvement alone, if it does occur in juvenile rheumatoid arthritis, would seem less liable to produce a progressive structural scoliosis. There can be no doubt that a more accurate radiological study of the spines of patients suffering from scoliosis in juvenile rheumatoid arthritis is needed to give a better understanding of this uncommon etiological factor.

\section{SUMMARY}

1. Eleven patients with juvenile rheumatoid arthritis, most of them young adults at a terminal stage, were found to have structural scoliosis with curves measuring between 20 and 80 degrees. 
2. The common feature was severe and protracted rheumatoid disease.

3. The characteristics of the spinal curves are analysed; the longer curves may have been caused by muscle imbalance and the shorter curves possibly by asymmetrical involvement of the inter-apophyseal joints.

4. It is suggested that juvenile rheumatoid arthritis is an unusual etiological factor of scoliosis.

The authors are deeply indebted to Professor Kauko Vainio and to Dr G. Dean MacEwen for permission to report their cases and for helpful criticism. They are also grateful to Professor André Vincent and to Professor Charles Nagant de Deuxchaisnes of Louvain for their advice and encouragement.

\section{REFERENCES}

Ansell, B. M., and Bywaters, E. G. L. (1956): Growth in Still's disease. Annals of the Rheumatic Diseases, 15, 295-319.

Ansell, B. M., Bywaters, E. G. L., and Lawrence, J. S. (1962): A family study in Still's disease. Annals of the Rheumatic Diseases, 21, 243-252.

CoBB, J. R. (1960): The problem of the primary curve. Journal of Bone and Joint Surgery, 42-A, 1413-1425.

Forestier, J., JACQUeline, F., and CANET, L. (1959): Le rhumatisme inflammatoire chronique de l'enfant. Rhumatologie (Paris), 11, 51-116.

Grokoest, A. W., SNyder, A. I., and Schlaeger, R. (1962): Juvenile rheumatoid arthritis. Boston: Little, Brown and Company. London: J. and A. Churchill Ltd.

JAMES, J. I. P. (1970): The etiology of scoliosis. Journal of Bone and Joint Surgery, 52-B, 410-419.

Köhler, A., and Zimmer, E. A. (1953): Grenzen des Normalen und Anfänge des Pathologischen im Röntgenbilde des Skelettes. 9e Auflage, p. 417. Stuttgart: Georg Thieme Verlag.

LaAksonen, A. L. (1966): A prognostic study of juvenile rheumatoid arthritis. Analysis of 544 cases. Acta paediatrica Scandinavica, supplement 166.

Le Baudour, J., and Freyberg, R. H. (1958): Contribution á l'étude de la polyarthrite chronique évolutive de l'enfant. Ses localisations cervicales. Semaine des Hôpitaux de Paris, 34, 1120-1129.

MARTEL, W., Holt, J. F., and CASsidy, J. T. (1962): Roentgenologic manifestations of juvenile rheumatoid arthritis. American Journal of Roentgenology, Radium Therapy and Nuclear Medicine, 88, 400-423.

Potter, T. A., Barkin, R., and Stillman, J. S. (1954): Occurrence of spondylitis in juvenile rheumatoid arthritis. Annals of the Rheumatic Diseases, 13, 364-365.

Rombouts, J. J., and Rombouts-Lindemans, C. (1971): Involvement of the hip in juvenile rheumatoid arthritis. Acta rheumatologica Scandinavica, 17, 248-267.

Shands, A. R., Jun., and Eisberg, H. B. (1955): The incidence of scoliosis in the State of Delaware. Journal of Bone and Joint Surgery, 37-A, 1243-1249.

Steinbrocker, O., Traeger, C. H., and Batterman, R. C. (1949): Therapeutic criteria in rheumatoid arthritis. Journal of the American Medical Association, 140, 659-662.

StILl, G. F. (1897): On a form of chronic joint disease in children. Medico-Chirurgical Transactions, 80, 47-59. Reprinted in Archives of Diseases in Childhood (1941), 16, 156-165.

ZAoussis, A. L., and JAMES, J. I. P. (1958): The iliac apophysis and the evolution of curves in scoliosis. Journal of Bone and Joint Surgery, 40-B, 442-453. 